\title{
Copeptin is not useful as a marker of malignant disease in the syndrome of inappropriate antidiuresis
}

\author{
Bettina Winzeler ${ }^{1,2, *}$, Michelle Steinmetz ${ }^{1,2, *}$, Julie Refardt ${ }^{1,2}$, Nicole Cesana-Nigro ${ }^{3}$, Milica Popovic ${ }^{1,2}$, \\ Wiebke Fenske ${ }^{4,5}$ and Mirjam Christ-Crain ${ }^{1,2}$ \\ ${ }^{1}$ Department of Endocrinology, Diabetology and Metabolismus, University Hospital Basel, Basel, Switzerland \\ ${ }^{2}$ Department Clinical Research, University of Basel, Basel, Switzerland \\ ${ }^{3}$ Department of Endocrinology and Diabetology, Bürgerspital Solothurn, Solothurn, Switzerland \\ 4Department of Endocrinology and Nephrology, University of Leipzig, Leipzig, Germany \\ ${ }^{5}$ Leipzig University Medical Center, IFB Adiposity Diseases, Leipzig, Germany
}

Correspondence should be addressed to B Winzeler: bettina.winzeler@usb.ch

*(B Winzeler and M Steinmetz contributed equally to this work)

\begin{abstract}
Objective: The syndrome of inappropriate antidiuresis (SIAD) is a common condition in hospitalized patients. It is crucial to establish the cause of SIAD, especially in order to exclude underlying malignancy. As malignant SIAD may be due to a paraneoplastic synthesis of arginine vasopressin, we hypothesized that its stable surrogate marker copeptin can be used as a diagnostic tool to differentiate between malignant and non-malignant SIAD.

Methods: Prospective observational study. We analyzed data from 146 SIAD patients of two different cohorts from Switzerland and Germany. Patients were included while presenting at the emergency department and underwent a standardized diagnostic assessment including the measurement of copeptin levels.

Results: Thirty-nine patients (median age: 63 years, 51\% female) were diagnosed with cancer-related SIAD and 107 (median age: 73 years, 68\% female) with non-malignant SIAD. Serum sodium levels were higher in cancer-related versus non-malignant SIAD: median (IQR) $124 \mathrm{mmol} / \mathrm{l}(120 ; 127)$ versus $120 \mathrm{mmol} / \mathrm{l}(117 ; 123)(P<0.001)$. Median (IQR) copeptin levels of patients with cancer-related SIAD were $11.1 \mathrm{pmol} / \mathrm{l}(5.2 ; 37.1)$ and $10.5 \mathrm{pmol} / \mathrm{l}$ (5.2; 25.2) with non-malignant SIAD $(P=0.38)$. Among different cancer entities, patients suffering from small-cell lung cancer showed the highest copeptin values, but overall no significant difference in copeptin levels between cancer types was observed $(P=0.46)$. Conclusions: Copeptin levels are similar in cancer-related and non-malignant SIAD. Therefore, Copeptin does not seem to be suitable as a marker of malignant disease in SIAD.
\end{abstract}

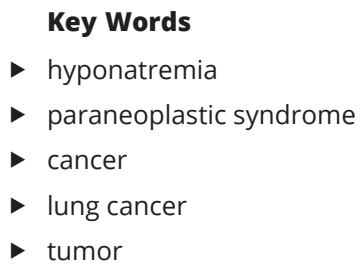

\section{Introduction}

Hyponatremia is the most common electrolyte disturbance in hospitalized patients (15-30\%) (1) and is associated with increased morbidity and mortality $(2,3)$. One of its main causes is the syndrome of inappropriate antidiuresis (SIAD), characterized by water retention and secondary natriuresis $(4,5)$. SIAD can be caused by a variety of conditions (infections, CNS disorders, drugs, pain or stress (6)) and to large degree by cancers, whereby https://ec.bioscientifica.com https://doi.org/10.1530/EC-19-0431 (c) 2020 The authors Published by Bioscientifica Ltd
This work is licensed under a Creative Commons Attribution-NonCommercial-NoDerivatives 4.0 Internationab ticense ifica.com at $04 / 26 / 2023 \quad 01: 45: 55 \mathrm{PM}$ 
it is postulated that arginine vasopressin (AVP) is produced paraneoplastically $(6,7,8)$. Differentiation between these etiologies is important, especially in order to exclude or detect an underlying malignancy which is present in approximately one-third of patients with SIAD (9). So far, there are no evidence-based guidelines for differential diagnosis, and current diagnostic strategies are not well characterized. Therefore, a simple, reliable predictive marker would be of great interest.

Copeptin, the c-terminal part of the precursor peptide of AVP, is increasingly used as a reliable surrogate marker of the unstable AVP $(10,11)$. Copeptin has been postulated and evaluated as a diagnostic tool in hyponatremia but showed limited utility to differentiate between SIAD and other causes of hyponatremia, such as hypovolemic and hypervolemic hyponatremia $(12,13,14)$. While in the latter two categories, copeptin levels are typically high; in SIAD (14) copeptin levels vary widely. In line with this, Zerbe et al. and later Fenske et al. described different SIAD subtypes according to different osmoregulatory defects $(15,16)$. The so-called subtype A, characterized by persistent high copeptin values ( $>38 \mathrm{pmol} / \mathrm{l})$, was primarily observed in patients with lung cancer (16). These results point to the long-standing idea of malignant SIAD being caused by autonomous extra-hypothalamic production of AVP (e.g. in lung cancer tissue) $(17,18)$. Indeed, previous data indicated AVP mRNA and AVP peptide production in small-cell lung cancer cell lines (19) and in vivo studies showed significant elevations of AVP (20) and copeptin (21) in cancer patients.

Based on these findings, we hypothesized that copeptin levels are higher in cancer-related SIAD compared to non-malignant SIAD, and we aimed to explore whether copeptin may be used as a diagnostic marker for malignant disease in patients with SIAD.

\section{Materials and methods}

\section{Study design}

We analyzed data from 146 SIAD patients from two different prospective observational studies from Switzerland and Germany. Both studies evaluated the utility of copeptin in the differential diagnosis of hypoosmolar hyponatremia; the respective study designs have previously been described in detail $(12,14)$. All subjects gave informed consent to take part in the studies, and the study was approved by the Ethics Committee of Basel/Aarau and the Ethics Committee of the University of Würzburg.

\section{Swiss cohort}

From June 2011 to August 2013, 298 adult patients admitted to the medical emergency department of the University Hospital Basel and Kantonsspital Aarau with a serum sodium value of $<125 \mathrm{mmol} / \mathrm{l}$ and serum osmolality of $<280 \mathrm{mosmol} / \mathrm{kg}$ were recruited (NCT01456533) (14). Of those patients, 104 were diagnosed with SIAD and included in the present study.

\section{German cohort}

From March to November 2007, 106 adult patients admitted to the medical emergency department of the University Hospital of Würzburg with a serum sodium value of $\leq 130$ $\mathrm{mmol} / \mathrm{l}$ and serum osmolality of $<280 \mathrm{mosmol} / \mathrm{kg}$ were recruited (NCT01341665) (12). Patients with impaired renal function (serum creatinine $>3.0 \mathrm{mg} / \mathrm{dl}$ ) and those whose previous pharmacotherapy could not be reliably specified were excluded. Of the remaining patients, 42 were categorized as SIAD and included in the present study.

\section{Clinical and laboratory assessment}

At admission, patient's medical history and symptoms, vital signs, body measures and fluid status were assessed and routine blood and urine samples were collected.

Additional blood samples for copeptin measurements were immediately drawn and stored at $-70^{\circ} \mathrm{C}$. All copeptin values were determined using a standard chemiluminescence sandwich immunoassay (B.R.A.H.M.S. Gmbh, Hennigsdorf/Berlin, Germany) (10). The lower detection limit of the assay was $0.4 \mathrm{pmol} / \mathrm{l}$ with a functional assay sensitivity $(<20 \%$ interassay coefficient of variation) of $1 \mathrm{pmol} / \mathrm{l}$.

\section{Diagnostic criteria and classification of SIAD}

The classification of SIAD was determined in a standardized way in both studies: an expert panel of at least two certified specialists was given access to all relevant clinical and laboratory patient information, covering the entire inpatient course. Importantly, new findings (e.g. new cancer diagnosis) arising during hospitalization and treatment response were included in the final classification.

Basic diagnostic criteria for SIAD included euvolemia, urine osmolality $>200 \mathrm{mmol} / \mathrm{l}$ and normal adrenal and thyroid function. Further criteria were considered if available: urinary sodium $>40 \mathrm{mmol} / \mathrm{l}$, fractional excretion of urea ( $>35 \%)$ and uric acid (>12\%).

This work is licensed under a Creative Commons Attribution-NonCommercial-NoDerivatives 4.0 Internationab ticense.ifica com at $04 / 26 / 2023 \quad 01: 45: 55 \mathrm{PM}$ 
Patients with SIAD were subclassified into cancerrelated SIAD and non-malignant SIAD. In the nonmalignant group, SIAD was further divided into the following categories: infectious SIAD, centrally induced SIAD, medication-induced SIAD and idiopathic SIAD.

For patients with cancer-related SIAD, the origin of the cancer and the disease stage (metastatic and nonmetastatic disease) were assessed.

\section{Study objectives}

The primary objective of this study was to compare copeptin levels in patients with cancer-related SIAD to those with non-malignant SIAD. Further objectives included the comparison of copeptin levels between the different cancer types and SIAD categories.

\section{Statistical analysis}

Baseline characteristics are described using summary characteristics. The difference in the baseline values between the two cohorts was calculated by applying a t-test. To test for differences in copeptin levels between patients with cancer-related and non-malignant SIAD, a linear regression model was fitted indicating the presence of malignant disease as explanatory and log-transformed copeptin levels as dependent variable. Due to rightskewness of copeptin values, copeptin was log-transformed and normality was checked by inspecting QQ-plots. To further analyze whether copeptin levels are predicted by different cancer subtypes, a linear model was fitted with log-transformed copeptin values as dependent and cancer type as explanatory variable. Only patients with malignant disease were included in this analysis. A $P$-value of $<0.05$ was considered to be statistically significant. Analyses and graphics were performed using the statistical software package R (22) and GraphPad Prism7.

\section{Results}

\section{Baseline characteristics}

In Table 1, baseline characteristics of both cohorts are provided. Of the total of 146 patients, 92 (63\%) were

Table 1 Descriptive table of the Swiss and German cohort.

\begin{tabular}{l}
\hline \\
\hline Characteristics \\
Number of SIAD patients \\
Female, $n$ (\%) \\
Median age (years) \\
Clinical parameters: median (IQR) \\
BMI \\
Systolic BP, mmHg \\
Diastolic BP, mmHg \\
Heartbeats/minute \\
Laboratory parameters: median (IQR) \\
Serum copeptin (pmol//) \\
Serum sodium (mmol/I) \\
Serum osmolality (mosmol/I) \\
Urine osmolality (mosmol/I) \\
Categories of SIAD \\
Cancer-related, $n$ (\%) \\
$\quad$ Metastatic disease, $n(\%)$ \\
Infections, $n(\%)$ \\
Central, $n(\%)$ \\
Medication, $n$ (\%) \\
Others, $n(\%)$ \\
Cancer types \\
Lung (SCLC), $n(\%)$ \\
Lung (others), $n(\%)$ \\
Gastrointestinal, $n$ (\%) \\
Hematological, $n(\%)$ \\
Others, $n(\%)$ \\
\hline
\end{tabular}

\begin{tabular}{c} 
Total \\
146 \\
$92(63 \%)$ \\
$69(60-78)$ \\
$23.4(20.7-26.3)$ \\
$136(120-157)$ \\
$77(67-84)$ \\
$74(65-84)$ \\
$10.3(5-26.6)$ \\
$121(117-124)$ \\
$254(247-262)$ \\
$423(327-546)$ \\
$39(27 \%)$ \\
$36(92 \%)$ \\
$17(12 \%)$ \\
$23(16 \%)$ \\
$45(31 \%)$ \\
$22(15 \%)$ \\
$11(28 \%)$ \\
$12(31 \%)$ \\
$7(18 \%)$ \\
$6(15.3 \%)$ \\
$3(8 \%)$ \\
\hline
\end{tabular}

\begin{tabular}{c}
\hline Swiss cohort \\
104 \\
$70(67 \%)$ \\
$71(61-78)$ \\
$23.5(20.7-26.3)$ \\
$143(125-161)$ \\
$75(66-84)$ \\
$77(67-86)$ \\
$10.6(5.4-27.2)$ \\
$120(116-122)$ \\
$251(242-258)$ \\
$402(326-496)$ \\
$19(18 \%)$ \\
$19(100 \%)$ \\
$9(9 \%)$ \\
$18(17 \%)$ \\
$43(41 \%)$ \\
$15(14 \%)$ \\
$8(42 \%)$ \\
$6(32 \%)$ \\
$2(11 \%)$ \\
$1(5 \%)$ \\
$2(11 \%)$ \\
\end{tabular}

\begin{tabular}{c}
\hline German cohort \\
42 \\
$22(53 \%)$ \\
$67(57-78)$ \\
$22.9(20.3-25.6)$ \\
$116(105-131.5)$ \\
$70(65-79)$ \\
$70(60-80)$ \\
$10(4.4-20.3)$ \\
$126(122-128)$ \\
$262(257-266)$ \\
$464(343-594)$ \\
\\
$20(48 \%)$ \\
$17(85 \%)$ \\
$8(19 \%)$ \\
$5(12 \%)$ \\
$2(5 \%)$ \\
$7(17 \%)$ \\
$3(15 \%)$ \\
$6(30 \%)$ \\
$5(25 \%)$ \\
$5(25 \%)$ \\
$1(5 \%)$ \\
\end{tabular}

Data are presented as mean and interquartile range (IQR) or as percentage (\%). BMI: body mass index, BP: blood pressure, SCLC: small cell lung cancer, SIAD: syndrome of inappropriate antidiuresis.

https://ec.bioscientifica.com https://doi.org/10.1530/EC-19-0431 (c) 2020 The authors Published by Bioscientifica Ltd

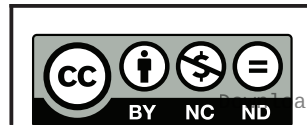

This work is licensed under a Creative Commons Attribution-NonCommercial-NoDerivatives 4.0 Internationab bicense.ifica . com at $04 / 26 / 2023 \quad 01: 45: 55 \mathrm{PM}$ 
Table 2 Descriptive table of patients with cancer-related and non-malignant SIAD.

\begin{tabular}{l}
\hline \\
\hline Characteristics \\
Number of SIAD patients, $n$ (\%) \\
Female, $n$ (\%) \\
Median age, years (IQR) \\
Clinical parameters: median (IQR) \\
BMI \\
Systolic BP, mmHg \\
Diastolic BP, mmHg \\
Heart beats/minute \\
Laboratory parameters: median (IQR) \\
Serum copeptin, pmol// \\
Serum sodium, mmol/I \\
Serum osmolality, mosmol// \\
Urine osmolality, mosmol/I
\end{tabular}

\begin{tabular}{c}
\hline Cancer-related SIAD \\
\hline $39(26.7 \%)$ \\
$20(51 \%)$ \\
$63(59-69)$ \\
$22.2(20.4-24.8)$ \\
$125(116-142)$ \\
$72(65-82)$ \\
$77(64-83)$ \\
$11.1(5.2-37.1)$ \\
$124(120-127)$ \\
$259(250-266)$ \\
$499(401-589)$
\end{tabular}

\begin{tabular}{c}
\hline Non-malignant SIAD \\
\hline $107(73.3 \%)$ \\
$72(68 \%)$ \\
$73(60-80)$ \\
$23.8(21.1-26.3)$ \\
$142(122-160)$ \\
$77(68-84)$ \\
$73(65-84)$ \\
$10.5(5.2-25.2)$ \\
$120(117-123)$ \\
$252(243-258)$ \\
$393(312-495)$
\end{tabular}

\begin{tabular}{c}
\hline P-value \\
\hline \\
\\
0.09 \\
0.09 \\
\\
0.75 \\
0.02 \\
0.24 \\
0.62 \\
\\
0.38 \\
$<0.001$ \\
0.02 \\
0.01
\end{tabular}

Data are presented as mean and interquartile range (IQR) or percentage (\%). $P<0.05$ is considered to be significant.

BP: blood pressure, SIAD: syndrome of inappropriate antidiuresis.

female and the median age in the population was 69 years - without a statistically significant difference between the two cohorts.

Overall, the median serum sodium level was 121 $\mathrm{mmol} / \mathrm{l}$ (IQR 117-124). According to the inclusion criteria, the median (IQR) serum sodium level was lower in the Swiss cohort, $120 \mathrm{mmol} / \mathrm{l}$ (116-122), compared to the German cohort, $126 \mathrm{mmol} / \mathrm{l}$ (122-128). German patients showed a higher median (IQR) urine osmolality compared to Swiss patients: $464 \mathrm{mosmol} / \mathrm{l}$ (343-594) versus 402 mosmol/1 (326-496), respectively.

Overall, median (IQR) copeptin level was $10.3 \mathrm{pmol} / \mathrm{l}$ (5-26.6), with similar values in both data sets.

According to SIAD categories, 39 (27\%) patients were found to have cancer-related SIAD with different proportions in the German (48\%) and the Swiss cohort (18\%). Similarly, frequencies of other SIAD categories also differed between the two cohorts, for example, medication induced SIADH was highly prevalent in the Swiss cohort (41\%), but not in the German cohort (5\%) (Table 1).

In the 39 patients with cancer-related SIAD, metastatic disease was present in $100 \%$ of the Swiss and in $85 \%$ of the German cohort. The remaining 15\% of the German patients suffered from hematologic diseases whose progression is not defined by metastases.

\section{Cancer-related versus non-malignant SIAD}

Patients with cancer-related SIAD tended to be younger (median 63 years) and less often female (51\%) compared to those with non-malignant SIAD (median 73 years, $68 \%$ female). Median (IQR) serum sodium levels were $124 \mathrm{mmol} / \mathrm{l}$ (120-127) in the cancer-related group compared to $120 \mathrm{mmol} / \mathrm{l}(117-123)$ in the non-malignant group. Serum sodium and osmolality as well as urine osmolality were all significantly higher in patients with cancer-related SIAD than in patients with non-malignant SIAD (Table 2).

Median (IQR) copeptin levels were not higher in patients with cancer-related versus non-malignant SIAD: $11.1 \mathrm{pmol} / 1$ (5.2-37.1), with a range from 0.95 to 380 $\mathrm{pmol} / \mathrm{l}$ versus 10.5 (5.2-25.2), with a range of 0.4 and $254.0 \mathrm{pmol} / \mathrm{l}$, respectively $(P=0.38$, Fig. 1 and Table 2$)$.

\section{Copeptin values according to cancer types}

When comparing copeptin levels between different cancer types (Fig. 2), overall no significant difference was observed $(P=0.46)$. We found slightly higher values in patients with small-cell lung cancer compared to other cancer entities, but without statistical significance $(P=0.43)$. The highest copeptin values were found in two patients with newly discovered, highly proliferative small-cell lung cancer (380 and $278.2 \mathrm{pmol} / \mathrm{l}$ ).

\section{Copeptin values in different SIAD categories}

Within the different categories of non-malignant SIAD, there was a large overlap in copeptin levels, with high values up to $>230 \mathrm{pmol} / \mathrm{l}$ in all categories (Fig. 3).

\section{Discussion}

The main finding of our study is that copeptin values vary widely in patients with cancer-related and non-malignant 


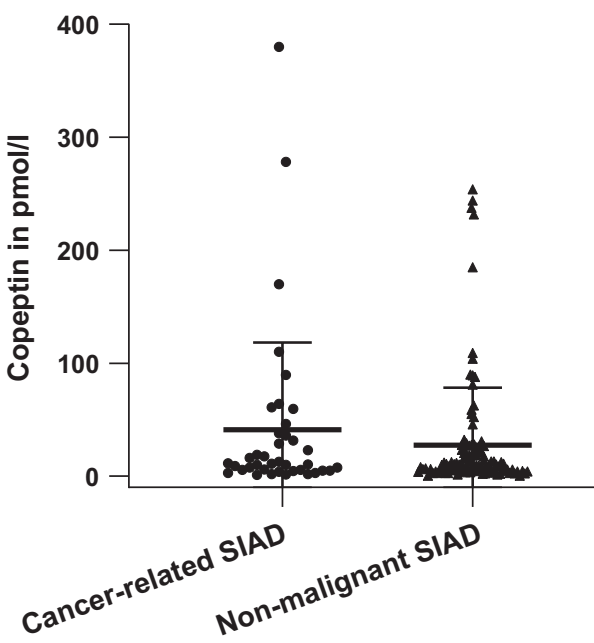

\section{Figure 1}

Copeptin values in patients with cancer-related and non-malignant SIAD. Boxplot: central line indicates the median; the upper and lower lines indicate the interquartile range.

SIAD and do not differ between the two groups. Similarly, we found no substantial difference of copeptin levels according to different cancer types or in the subcategories of SIAD.

The highest copeptin values (380 and $278 \mathrm{pmol} / \mathrm{l}$ ) were observed in two patients with small-cell lung cancer. In fact, small-cell lung cancer is the best-characterized tumor entity of paraneoplastic AVP release by neuroendocrine tumor cells $(19,23,24)$. The high copeptin values in these patients may therefore represent ectopic AVP production and correspond to the previously described

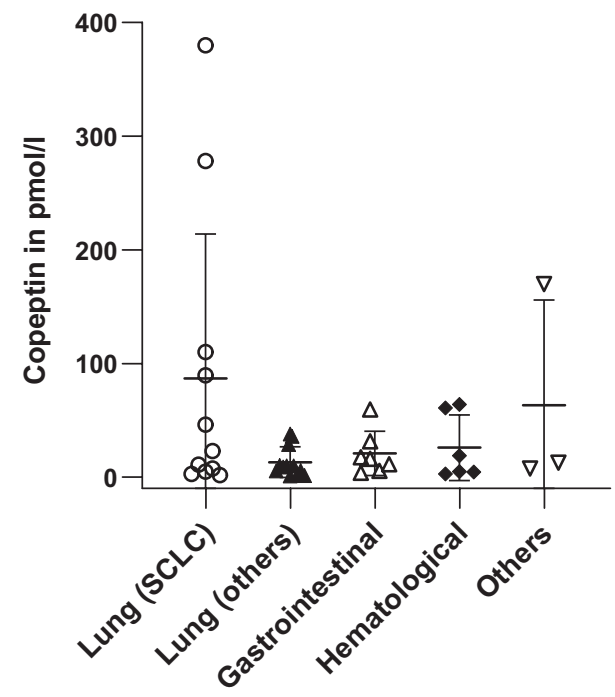

Figure 2

Copeptin values according to cancer types. Boxplot: central line indicates the median; the upper and lower lines indicate the interquartile range.

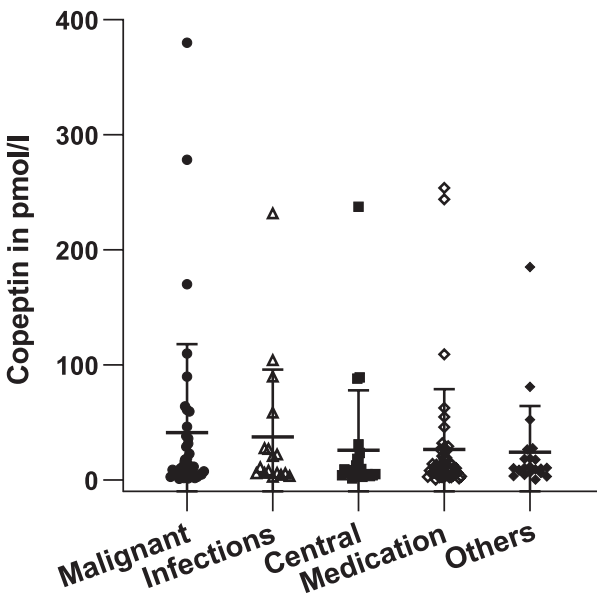

Figure 3

Copeptin values according to SIAD categories. Boxplot: central line indicates the median; the upper and lower lines indicate the interquartile range.

SIAD 'subtype A', characterized by erratic elevated AVP/ copeptin levels $(15,16)$. Accordingly, in previously reported cases adjudicated to this subtype, copeptin levels were consistently above a cut-off of $38 \mathrm{pmol} / \mathrm{l}$, and in four of five described cases even around 200-300 pmol/1 (16). In contrast, in our small-cell lung cancer patients, the majority of patients had copeptin levels below 38 pmol/l. Thus, even in the subgroup of small-cell lung cancer, where all patients had active and mostly extended disease, copeptin levels were not throughout markedly elevated but varied widely. In the remaining cancer types, copeptin levels were in the IQR of 5.5-29 pmol/1.

There are several possible explanations for our findings. First, in the context of small-cell lung cancer and paraneoplastic phenomena hormones other than AVP (e.g. ANP) may play a role in hyponatremia $(25,26)$. Second, hyponatremia, and especially SIAD, is highly prevalent in patients with all types of cancer $(5-30 \%)(8,27,28$, 29). Besides ectopic hormone secretion, hyponatremia in cancer patients may be caused by the same conditions as in non-cancer patients: comorbidities, medication or symptoms such as vomiting, nausea, dehydration or stress. Of note, cancer patients are often polymedicated (e.g. chemotherapy such as vincristine and cisplatin, pain killers) or in an unstable condition and may, therefore, be particularly prone to hyponatremia (30). Third, irrespective of SIAD, copeptin is known to be elevated due to stress and acute conditions such as pneumonia, stroke or heart failure $(31,32,33)$. All patients in our study were recruited in an acute setting when presenting at the emergency department. Thus, many of our patients might have had high copeptin values due to physical and 
psychological stress. As previously shown by our group, the non-osmotic, stress-related copeptin stimulus in acute hospitalized hyponatremic patients may overrule the osmotic impulse $(13,14)$.

Of note, markedly elevated copeptin levels above 230 pmol/l were occasionally observed in all subcategories of non-malignant SIAD. These patients suffered from different health issues (i.e. acute exacerbation of COPD, nausea and vomiting, polymedication).

According to the Hyponatremia Registry, approximately one-third of euvolemic hyponatremia cases are cancer related with lung cancer as the most common cancer type (around 50\%) (9). The high prevalence of cancer in SIAD is also demonstrated by our results with $27 \%$ cancer-related SIAD (of which $59 \%$ were due to lung cancer).

Interestingly, there were considerably more cases with cancer-related SIAD in the German compared to the Swiss cohort (48\% vs 18\%), and the cancer types varied between the cohorts. The main difference of our two cohorts was the severity of hyponatremia according to the inclusion criteria: serum sodium $<135 \mathrm{mmol} / \mathrm{l}$ in the German and $<125 \mathrm{mmol} / \mathrm{l}$ in the Swiss study. The high number of gastrointestinal and hematologic cancers in German patients with less pronounced hyponatremia corresponds to the findings of a Danish study observing that hematologic cancers are often associated with only mild hyponatremia (130-135 mmol/l), gastrointestinal cancer with moderate hyponatremia (125-129 mmol/l) and pulmonary as well as head and neck cancers with profound hyponatremia ( $<125 \mathrm{mmol} / \mathrm{l})(28)$.

Indeed, the severity of hyponatremia may differ according to SIAD categories, as previously observed in our Swiss hyponatremia cohort: lower sodium values $(<120$ $\mathrm{mmol} / \mathrm{l}$ ) were more often associated with non-malignant hyponatremia categories (especially medication-induced SIAD) than higher levels (34). This observation, however, contradicts the finding of balanced hyponatremia severity in different SIAD categories as found in the international Hyponatremia Registry (9).

Otherwise, our results are mostly in concordance with the Hyponatremia Registry (9): patients with malignancy were generally younger, were more often male and had higher levels of urine osmolality than patients with nonmalignant disease.

Some limitations have to be mentioned: the classification of hyponatremia and SIAD into different etiological categories remains a challenge as hyponatremia is often multifactorial and there is no reliable diagnostic standard. Therefore, even though adjudication was performed by experts and in a standardized manner, patients may have been misclassified. Further, despite the large number of SIAD patients studied, only 39 (27\%) had an active malignancy. Of those, cancer origin was very heterogeneous, leading to a very limited number in the various subcategories of cancer types.

A suitable diagnostic marker should be sensitive at an early stage of a cancer-related disease. Our patients with solid cancers were all in advanced stages, and we are therefore not able to draw conclusions about copeptin values as a diagnostic tool in an early phase of disease.

Finally, copeptin measurements were performed in an acute setting, where the stress-induced copeptin stimulus may overrule or confound the paraneoplastic or osmotic stimulus.

The strength of our study comprises the prospective data collection which allowed insights in the distribution of copeptin values in well-characterized SIAD patients with and without malignancy.

In summary, copeptin levels widely overlap in patients with cancer-related and non-malignant SIAD. This may be explained by the heterogeneity of SIAD and the multifarious factors leading to unspecific copeptin elevations in the acute setting. The use of copeptin as a marker to detect cancer-related disease in SIAD patients can therefore not be recommended.

\section{Declaration of interest}

The authors declare that there is no conflict of interest that could be perceived as prejudicing the impartiality of the research reported.

\section{Funding}

Laboratory measurement of copeptin was funded by Thermo Fisher Scientific.

\section{Data availability statement}

The data that support the findings of this study are available from the corresponding author upon reasonable request.

\section{Acknowledgements}

We thank the associated study teams in Basel, Aarau and Würzburg for the access to patient data and the helpful support during the creation of this article.

\section{References}

1 Upadhyay A, Jaber BL \& Madias NE. Epidemiology of hyponatremia. Seminars in Nephrology 200929 227-238. (https://doi.org/10.1016/j. semnephrol.2009.03.004)

2 Waikar SS, Mount DB \& Curhan GC. Mortality after hospitalization with mild, moderate, and severe hyponatremia. American Journal of Medicine 2009122 857-865. (https://doi.org/10.1016/j. amjmed.2009.01.027) 
3 Holland-Bill L, Christiansen CF, Heide-Jorgensen U, Ulrichsen SP, Ring T, Jorgensen JO \& Sorensen HT. Hyponatremia and mortality risk: a Danish cohort study of 279508 acutely hospitalized patients. European Journal of Endocrinology 2015173 71-81. (https://doi. org/10.1530/EJE-15-0111)

4 Ellison DH \& Berl T. Clinical practice. The syndrome of inappropriate antidiuresis. New England Journal of Medicine 2007356 2064-2072. (https://doi.org/10.1056/NEJMcp066837)

5 Schwartz WB, Bennett W, Curelop S \& Bartter FC. A syndrome of renal sodium loss and hyponatremia probably resulting from inappropriate secretion of antidiuretic hormone. American Journal of Medicine 195723 529-542. (https://doi.org/10.1016/00029343(57)90224-3)

6 Hirata Y, Matsukura S, Imura H, Yakura T \& Ihjima S. Two cases of multiple hormone-producing small cell carcinoma of the lung: coexistence of tumor ADH, ACTH, and beta-MSH. Cancer 197638 2575-2582. (https://doi.org/10.1002/10970142(197612)38:6<2575::aid-cncr2820380651>3.0.co;2-b)

7 List AF, Hainsworth JD, Davis BW, Hande KR, Greco FA \& Johnson DH. The syndrome of inappropriate secretion of antidiuretic hormone (SIADH) in small-cell lung cancer. Journal of Clinical Oncology 19864 1191-1198. (https://doi.org/10.1200/ JCO.1986.4.8.1191)

8 Sørensen JB, Andersen MK \& Hansen HH. Syndrome of inappropriate secretion of antidiuretic hormone (SIADH) in malignant disease. Journal of Internal Medicine 1995238 97-110. (https://doi. org/10.1111/j.1365-2796.1995.tb00907.x)

9 Burst V, Grundmann F, Kubacki T, Greenberg A, Rudolf D, Salahudeen A, Verbalis J \& Grohe C. Euvolemic hyponatremia in cancer patients. Report of the Hyponatremia Registry: an observational multicenter international study. Supportive Care in Cancer 201725 2275-2283. (https://doi.org/10.1007/s00520-017-3638-3)

10 Morgenthaler NG, Struck J, Alonso C \& Bergmann A. Assay for the measurement of copeptin, a stable peptide derived from the precursor of vasopressin. Clinical Chemistry 200652 112-119. (https://doi.org/10.1373/clinchem.2005.060038)

11 Christ-Crain M \& Fenske W. Copeptin in the diagnosis of vasopressin-dependent disorders of fluid homeostasis. Nature Reviews Endocrinology 201612 168-176. (https://doi.org/10.1038/ nrendo.2015.224)

12 Fenske W, Stork S, Blechschmidt A, Maier SG, Morgenthaler NG \& Allolio B. Copeptin in the differential diagnosis of hyponatremia. Journal of Clinical Endocrinology and Metabolism 200994 123-129. (https://doi.org/10.1210/jc.2008-1426)

13 Nigro N, Müller B, Morgenthaler N, Fluri F, Schütz P, Neidert S, Stolz D, Bingisser R, Tamm M, Christ-Crain M, et al. The use of copeptin, the stable peptide of the vasopressin precursor, in the differential diagnosis of sodium imbalance in patients with acute diseases. Swiss Medical Weekly 2011141 w13270. (https://doi. org/10.4414/smw.2011.13270)

14 Nigro N, Winzeler B, Suter-Widmer I, Schuetz P, Arici B, Bally M, Blum CA, Nickel CH, Bingisser R, Bock A, et al. Evaluation of copeptin and commonly used laboratory parameters for the differential diagnosis of profound hyponatraemia in hospitalized patients: 'the Co-MED Study'. Clinical Endocrinology 201786 456-462. (https://doi.org/10.1111/cen.13243)

15 Zerbe R, Stropes L \& Robertson G. Vasopressin function in the syndrome of inappropriate antidiuresis. Annual Review of Medicine 198031 315-327. (https://doi.org/10.1146/annurev. me.31.020180.001531)

16 Fenske WK, Christ-Crain M, Horning A, Simet J, Szinnai G, Fassnacht M, Rutishauser J, Bichet DG, Stork S \& Allolio B. A copeptin-based classification of the osmoregulatory defects in the syndrome of inappropriate antidiuresis. Journal of the American Society of Nephrology 201425 2376-2383. (https://doi.org/10.1681/ ASN.2013080895)
17 George JM, Capen CC \& Phillips AS. Biosynthesis of vasopressin in vitro and ultrastructure of a bronchogenic carcinoma. Patient with the syndrome of inappropriate secretion of antidiuretic hormone. Journal of Clinical Investigation 197251 141-148. (https://doi. org/10.1172/JCI106784)

18 Amatruda TT, Mulrow PJ, Gallagher JC \& Sawyer WH. Carcinoma of the lung WITH inappropriate antidiuresis. Demonstration of antidiuretichormone-like activity in tumor extract. New England Journal of Medicine 1963269 544-549. (https://doi.org/10.1056/NEJM196309122691102)

19 Gross AJ, Steinberg SM, Reilly JG, Bliss DP, Brennan J, Le PT, Simmons A, Phelps R, Mulshine JL \& Ihde DC. Atrial natriuretic factor and arginine vasopressin production in tumor cell lines from patients with lung cancer and their relationship to serum sodium. Cancer Research 199353 67-74.

20 Odell WD \& Wolfsen AR. Humoral syndromes associated with cancer. Annual Review of Medicine 197829 379-406. (https://doi. org/10.1146/annurev.me.29.020178.002115)

21 Wuttke A, Dixit KC, Szinnai G, Werth SC, Haagen U, Christ-Crain M, Morgenthaler N \& Brabant G. Copeptin as a marker for argininevasopressin/antidiuretic hormone secretion in the diagnosis of paraneoplastic syndrome of inappropriate ADH secretion. Endocrine 201344 744-749. (https://doi.org/10.1007/s12020-013-9919-9)

22 R Development Core Team. R: A Language and Environmentfor Statistical Computing. R Foundation for Statistical Computing, 2018.

23 DeLellis RA \& Xia L. Paraneoplastic endocrine syndromes: a review. Endocrine Pathology 200314 303-317. (https://doi.org/10.1385/ ep:14:4:303)

24 Hansen O, Sørensen P \& Hansen KH. The occurrence of hyponatremia in SCLC and the influence on prognosis: a retrospective study of 453 patients treated in a single institution in a 10-year period. Lung Cancer 201068 111-114. (https://doi. org/10.1016/j.lungcan.2009.05.015)

25 Chute JP, Taylor E, Williams J, Kaye F, Venzon D \& Johnson BE. A metabolic study of patients with lung cancer and hyponatremia of malignancy. Clinical Cancer Research 200612 888-896. (https://doi. org/10.1158/1078-0432.CCR-05-1536)

$26 \mathrm{Wu}$ F \& Wu Q. Corin-mediated processing of pro-atrial natriuretic peptide in human small cell lung cancer cells. Cancer Research 2003 63 8318-8322.

27 Goldvaser H, Rozen-Zvi B, Yerushalmi R, Gafter-Gvili A, Lahav M \& Shepshelovich D. Malignancy associated SIADH: characterization and clinical implications. Acta Oncologica 201655 1190-1195. (https://doi.org/10.3109/0284186X.2016.1170198)

28 Selmer C, Madsen JC, Torp-Pedersen C, Gislason GH \& Faber J. Hyponatremia, all-cause mortality, and risk of cancer diagnoses in the primary care setting: a large population study. European Journal of Internal Medicine 201636 36-43. (https://doi.org/10.1016/j. ejim.2016.07.028)

29 Holland-Bill L, Christiansen CF, Farkas DK, Donskov F, Jørgensen JOL \& Sørensen HT. Diagnosis of hyponatremia and increased risk of a subsequent cancer diagnosis: results from a nationwide populationbased cohort study. Acta Oncologica 201857 522-527. (https://doi. org/10.1080/0284186X.2017.1378430)

30 Berardi R, Santoni M, Rinaldi S, Nunzi E, Smerilli A, Caramanti M, Morgese F, Torniai M, Savini A, Fiordoliva I, et al. Risk of hyponatraemia in cancer patients treated with targeted therapies: a systematic review and meta-analysis of clinical trials. PLOS ONE 2016 11 e0152079. (https://doi.org/10.1371/journal.pone.0152079)

31 Katan M \& Christ-Crain M. The stress hormone copeptin: a new prognostic biomarker in acute illness. Swiss Medical Weekly 2010140 w13101. (https://doi.org/10.4414/smw.2010.13101)

32 Jochberger S, Morgenthaler NG, Mayr VD, Luckner G, Wenzel V, Ulmer H, Schwarz S, Hasibeder WR, Friesenecker BE \& Dünser MW. Copeptin and arginine vasopressin concentrations in critically ill patients. Journal of Clinical Endocrinology and Metabolism 200691 4381-4386. (https://doi.org/10.1210/jc.2005-2830) 
33 Balling L, Kistorp C, Schou M, Egstrup M, Gustafsson I, Goetze JP, Hildebrandt P \& Gustafsson F. Plasma copeptin levels and prediction of outcome in heart failure outpatients: relation to hyponatremia and loop diuretic doses. Journal of Cardiac Failure 201218 351-358. (https://doi.org/10.1016/j.cardfail.2012.01.019)
34 Winzeler B, Jeanloz N, Nigro N, Suter-Widmer I, Schuetz P, Arici B, Bally M, Blum C, Bock A, Huber A, et al. Long-term outcome of profound hyponatremia: a prospective 12 months follow-up study. European Journal of Endocrinology 2016175 499-507. (https://doi. org/10.1530/EJE-16-0500)

Received in final form 25 November 2019

Accepted 2 December 2019

Accepted Manuscript published online 3 December 2019 (c) 2020 The authors Published by Bioscientifica Ltd 